\title{
Technology for Hearing Evaluation
}

\author{
Josefina Gutierrez \\ National Rehabilitation Institute \\ Mexico
}

\section{Introduction}

The hearing system is composed of several components that, by means of a physiological process, break down the broad spectrum of frequencies and intensities of sounds from the environment (speech, music, signals and noise) into frequency components and temporal patterns. These acoustic signals are transmitted to the temporal lobes of the Central Nervous System by electric stimuli to generate the neural message (Salesa et al., 2005). The hearing process utilizes acoustic, mechanical and electrical principles, and in addition analyzes sound waves, removes noise and compares these with signals that have been previously registered in the memory of the subject. In this manner, we are able to know when a person is speaking, when we are hearing a musical note from a violin or a flute, or when a bird is singing.

The auditory system possesses a wide dynamic range for perceiving sounds; humans with normal hearing detect tonal frequencies from $20 \mathrm{~Hz}$ to $20 \mathrm{kHz}$. Acoustic intensity is proportional to sound vibration amplitude. Commonly, sound intensity is measured in terms of decibels as $\mathrm{dB}=10 \log \left(I / I_{0}\right)$, where $I_{0}$ is the reference intensity, or equivalently for acoustic pressure, $\mathrm{dB}=20 \log \left(P / P_{0}\right)$, where $P_{0}$ is the reference pressure (in Pa). Tonality represents the number of vibrations in time and is measured in cycles/sec or Hz. Timbre characterizes all of the harmonics overheard in a clear sound, allowing differentiation between two sounds with the same tonality and intensity.

The dynamic range at $2-4 \mathrm{kHz}$, the span between threshold and pain, is approximately 120 $\mathrm{dB}$. The minimum threshold for sound occurs between 2 and $5 \mathrm{kHz}$ and is approximately $20 \mu \mathrm{Pa}$. At the low end of the auditory spectrum, the threshold is $80 \mathrm{~dB}$ higher, while at the high end, it is $70 \mathrm{~dB}$ higher. Intensity differences of $1 \mathrm{~dB}$ can be detected, while frequency differences of 2-3 Hz can be detected at frequencies below $3 \mathrm{kHz}$ (Aitkin, 1990).

Sounds are normally transmitted both by Air conduction (AC), and by Bone conduction (BC). Conduction of sound starts in the pinna or auricle and passes through the external auditory canal on its way to the eardrum, where sounds are amplified to frequencies ranging from 5,000-6,000 $\mathrm{Hz}$ at $20 \mathrm{~dB}$. Later, the pressure and strength of the sound wave vibration that reaches the tympanic membrane, particularly of low frequencies of up to 1,500 $\mathrm{Hz}$, are amplified in the middle ear. The acoustic vibration of the sound is thus transformed into a mechanical vibration to be transmitted to the organ of Corti, located in the cochlear duct. The cochlea is a hydromechanical frequency analyzer whose major role is to turn the acoustic signal into a frequency map through which each frequency is assigned to certain 
groups of receptor cells and their nerve fibers. The cochlear nerve innervates the organ of Corti; it possesses myelinized efferent fibers that carry spatial orientation information from the cochlea to the brain. Efferent signals are amplified and transmitted, frequency discrimination is increased, acoustic otoemissions originate, and mechanical changes produced in the liquid medium of the sound waves are detected (Steele et al., 2000).

Hearing loss can occur at any age. Otorhinolaryngologists, surgeons, and audiologists with assistance technology are readily able to identify different degrees of hearing loss. Children and adults experiencing significant hearing loss suffer specific problems and may need special assistance. Early identification of hearing loss and its treatment is essential for successful speech development, the child's intellectual growth and the adult's social integration.

Hearing impairment is caused by either loss in sensitivity (loss in perceived loudness), loss in the ability to discriminate different speech sounds, or both. Loss of loudness may be due to either increased mechanical impedance between the outer and inner ear or reduced sensitivity of the sensory hearing organ. Loss of the discrimination ability is basically associated with damage to the sensory organ, although other neural structures at higher levels may also be involved.

\section{Audiologic evaluation technology}

Several subjective and objective methods to assess hearing disorders are available, depending on the individual's age, hearing level and condition type. Among other things, evaluation must be conducted for cochlear integrity, acoustic impedance, and screening of hearing of newborns and infants.

With ever changing technology and new methodologies in healthcare, available for addressing the specific needs of adult and pediatric populations, hearing technology represents not only devices for clinicians' practice, but also devices to meet the high level of need for diagnostic techniques, audiologic rehabilitation, treatment methodologies, and special issues in researching the needs of patients (Montano \& Spitzer, 2009).

\subsection{Subjective evaluation (technology)}

Subjective hearing tests (Miller, 2006) are available for performing a rough estimate of the grade of hearing loss. These tests do not provide a quantitative report of the patient's hearing status, but rather comprise a method with practical clinical value for exploring the cochlea in order to determine location rather than intensity of the damage; results must be evaluated in conjunction with quantitative hearing evaluation. These include the following:

\subsubsection{Acumeter}

Instrumental acumetry (see Figure 1), which employs the diapason to assess hearing acuity, guarantees limited precision (Marullo et al., 1967). This instrument "tuning fork" produces sounds with frequencies between 16 and $4,096 \mathrm{~Hz}$ from octave to octave. This is a U-shaped acoustic resonator that resonates at a specific constant on a frequency-related scale when set to vibrate by striking it against a surface or with an object emitting a pure tone. There are three mean tests: 
The Schwabach test determines BC duration. The instrument is placed on the anterosuperior region of the mastoid. Normal duration is $20 \mathrm{sec}$. The Schwabach test makes a comparison between bone conduction of the patient and the examiner. The diapason is placed between the patient and examiner and a sound is created. If the patient can no longer hear the sound even though the examiner can hear it, it is indicative of sensory neural loss; if the examiner stops hearing the sound and the patient continues to hear it, it suggests conductive loss. However, this test is completely dependent on the hearing powers of the examiner. In conduction hypoacusis - the duration is prolonged, while in sensory neural hypoacusis, the duration is shortened.

The Weber test utilizes the low frequency of the instrument $(126 \mathrm{~Hz})$, which is placed on vertex. Normally the vibration is heard equally in both ears. This is a common medical test conducted in the physician's office in which a comparison is made between two hearings. In the first, the base of the tuning fork is applied to the bone and hearing is elicited after this. When the sound is completely inaudible, the vibrating top is brought near the external ear canal. If there is a positive value, it is considered that there is an air-bone gap due to which there is a conductive loss.

The Rinne test employs the diapason as initially placed near the ear to explore aerial conduction and after that, on the mastoid to explore bone conduction. Normally, air conduction is better than bone conduction. With $\mathrm{BC} / \mathrm{AC}=1 / 2$, the Rinne test is normally positive. In this test, a $512 \mathrm{~Hz}$ tuning fork is placed on the forehead of the patient. An ipsilateral conductive hearing loss is occurred if the sound appears to be louder on one side than on the other. A contralateral sensorineural hearing loss may also be determined by use of this test.
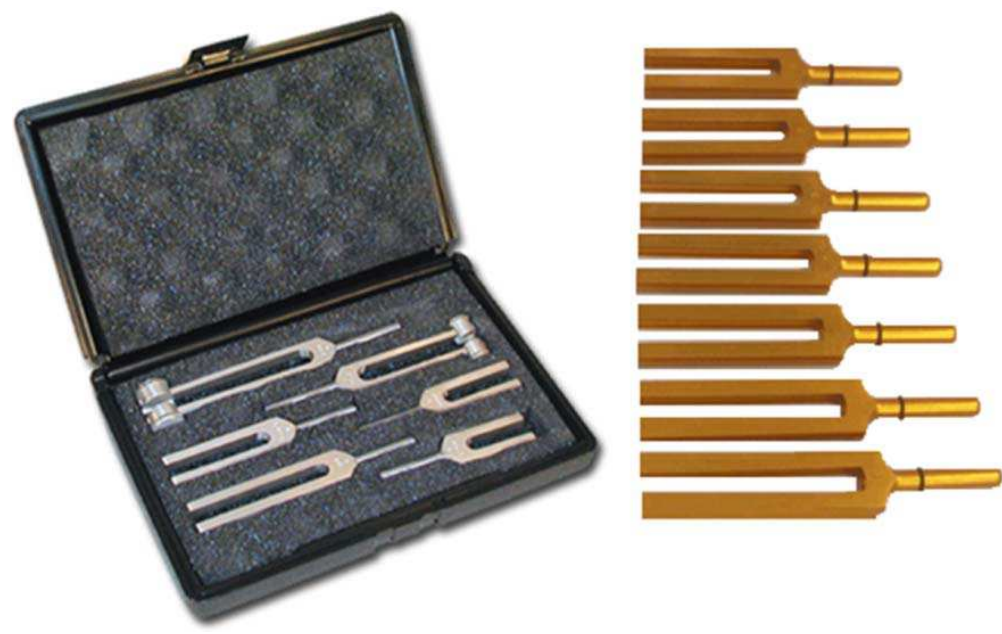

Fig. 1. Set of tuning fork

\subsubsection{Speech perception test}

This test uses words that the subject hears through headphones and he/she is required to identify them. This test depends on the knowledge of language; it must be adjusted to both 
adult and pediatric populations. It is categorized according to whether the words are aimed at evaluating detection level ability, syllable, phoneme, word, or sentence perception (Australian Hearing Group, 2001). Additionally, it is designed to provide a useful overview of the key features (e.g., target hearing-impaired group, clinical application) of each of the tests and thereby assists the Audiologist in selecting the appropriate speech perception test/s for the individual patient and the specific clinical situation.

\subsubsection{Acoustic reflex test}

The acoustic reflex test measures the contraction of the stapedius, a tiny muscle in the middle ear, in response to loud sounds, which occurs under normal conditions when a sufficiently intense sound is presented to the auditory pathway. This muscle contraction causes a stiffening of the ossicular chain, which alters the compliance of the middle ear system. When stimulus presentation and measurement are effected on the same ear by means of the probe tone, this acoustical reflex is referred to as an ipsilateral acoustic reflex. When stimulus presentation and measurement are effected on opposite ears, the reflex is referred to as a contralateral acoustic reflex.

Stimulus tones of varying intensities of 500,1000, 2000 or $4000 \mathrm{~Hz}$ are presented as short bursts. If a change in compliance greater than $0.05 \mathrm{ml}$ is detected, a reflex is considered to be present. Because this is an extremely small compliance change, any movement of the probe during the test may produce an artifact (false response). The test result is recorded as Pass/No Response in graphic form (MAICO, 2007). The level of loudness aids in identifying the location of the problem along the auditory pathway.

\subsubsection{Scope evaluation}

Scope evaluation utilizes a light emitted by an otoscope. The examiner is able to look into the outer and middle ear through a lens on the rear of the instrument and to screen for disease including otitis or infection during regular clinical check-ups. Figure 2 depicts the

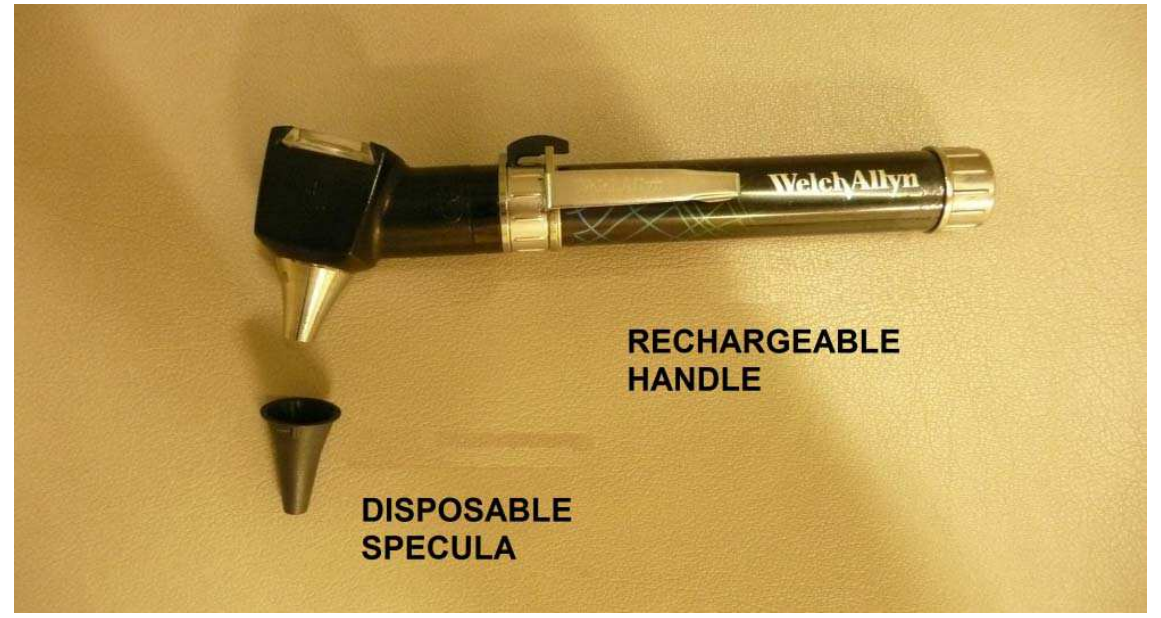

Fig. 2. Welch-Allyn handle otoscope 
Welch-Allyn otoscope (Golfain et al., 2008), which is a small hand-held instrument. It has a light that is directed through a funnel-like tip to illuminate the ear canal for examination. The funnel-like tip is called speculum. The specula are disposable and come in sizes for average adult ear canals. The otoscope is powered by a rechargeable battery located in the handle; the handle is detachable and can be plugged into a standard wall outlet for recharging.

\subsection{Objective evaluation (technology)}

Diagnostic equipment can help to identify different degrees of hearing loss in a more quantitative fashion. There are several techniques that are implemented in medical equipment for screening of hearing. The most widely used initial screen involves a puretone, air-conduction hearing test or audiometry, followed by tympanometry, otoacoustic emissions, multilingual speech audiometry, and stem cell evoked potentials.

Hearing testing is conducted in the audiometry testing chamber; a special sound booth is built into this room, which must be constructed based on testing guidance described in the ASTM E336 "Standard Test Method for measurement of Airborne Sound Insulation in Buildings" (ASTM E336-10, 2011). This triangular-shaped booth is designed to ensure that the sound levels inside are sufficiently quiet to permit accurate hearing-threshold measurements. In addition to the sound booth, the examination room possesses several other features designed to reduce sound levels in the room further, as shown in Figure 3. These include sound dampening materials on the interior walls of the examination room and a rubber seal on the exterior door.

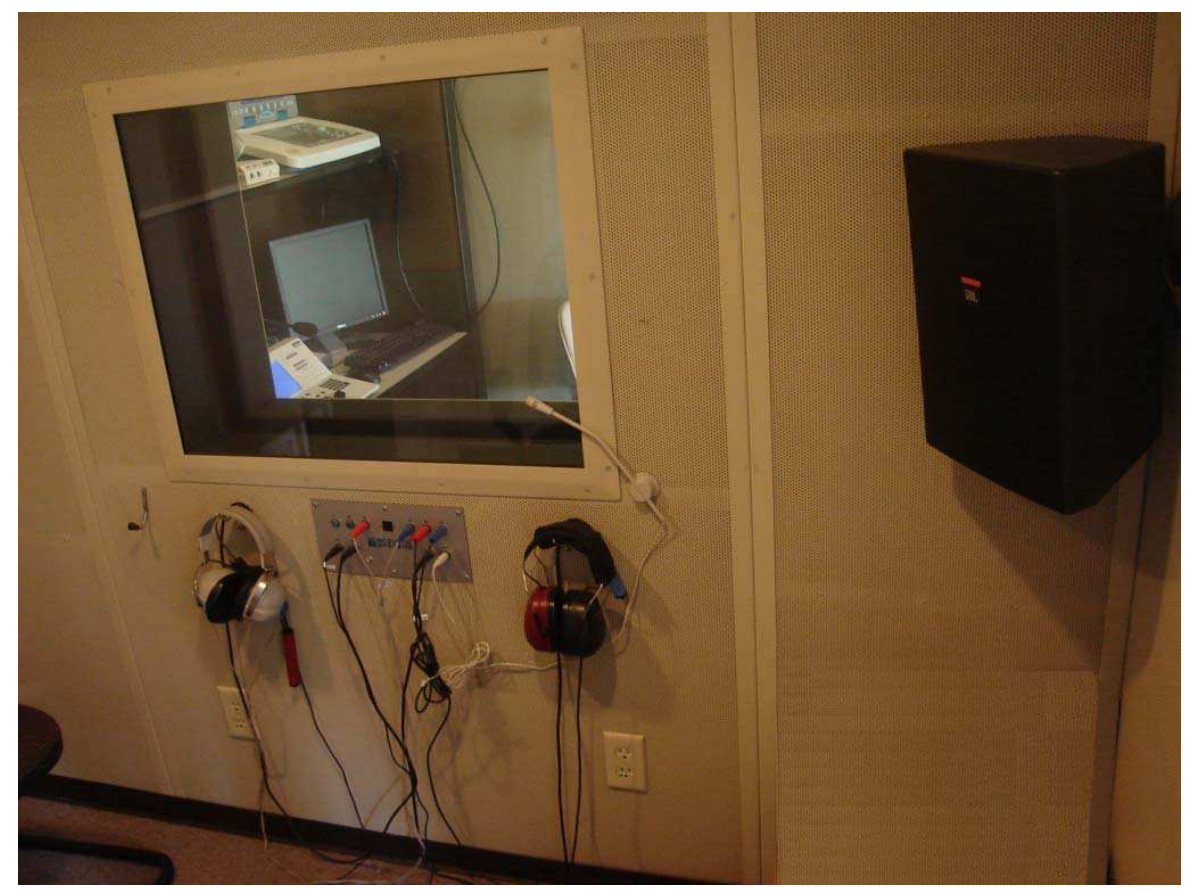

Fig. 3. Anaechoic Chamber for audiometry test. 
The testing suite consists of two adjoining rooms: one of single-wall construction, and the other, of double-wall construction. The double portion of the suite is the subject of the noise reduction test that includes the following: 1) generating a high-volume controlled sound field outside the testing chamber; 2) measuring the sound pressure level at the outer wall; 3) measuring the attenuated sound-pressure level of the controlled sound field inside the test chamber, and 4) subtracting internal from the external sound-pressure levels while making corrections for the interior ambient sound pressure level (Acoustic Systems MD, 2000).

\subsubsection{Pure-tone audiometry and logoaudiometry}

The Audiometry study is used to diagnose the degree and type of hearing loss by determining the faintest tones that a person can hear at selected pitches; the measuring equipment utilized is called audiometer. This device emits a pure tone by means of a fixedfrequency oscillator calibrated at the decibel hearing level (National Health and Nutrition Examination Survey, 2003); frequencies $(125-8000 \mathrm{~Hz})$ and intensities $(0-110 \mathrm{~dB})$ which can be varied. This unit is controlled by a microprocessor that is sometimes available as a handheld Windows-driven instrument and possesses high accuracy and efficiency (Khandpur, 2005). Such systems can be also employed with bone vibrators to test conductive hearing mechanisms. A pair of headphones is attached, and a test subject feedback button indicates when the subject has heard the sound. On the one hand, audiometry measures hearing thresholds and oral audiometry or logoaudiometry (Aguilera et al., 1997), considered to be a subjective evaluation, is defined by the capacity to evaluate the human speech understanding consists of supplying the patient with words at different energies that aid in recognizing acoustical features and in providing clues concerning the etiology of the hearing loss. On the other hand, audiometry includes supraliminal tests such as SISI, Fowler, Tone Decay, or Békésy, to suggest the sensorineural damage (Ghani, 2005). Figures 4 and 5 ilustrate the SISI and Békésy tests.

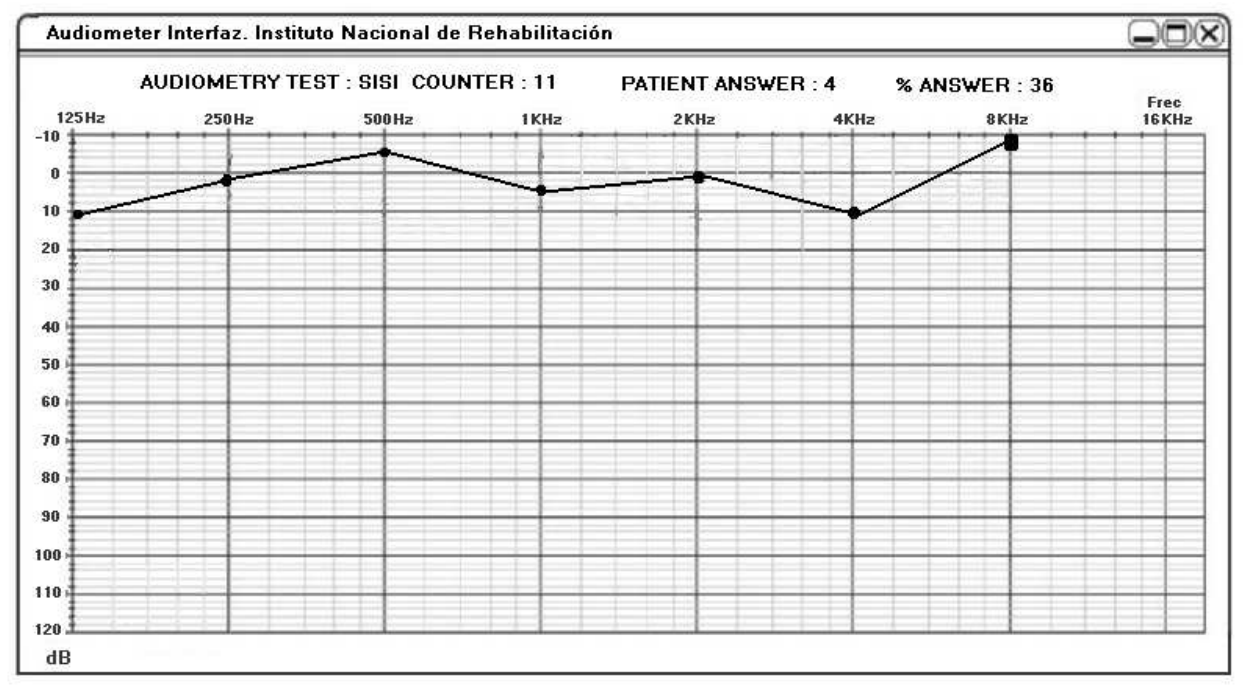

Fig. 4. A patient's SISI Graph with score value (Gutierrez et al., 2009) 


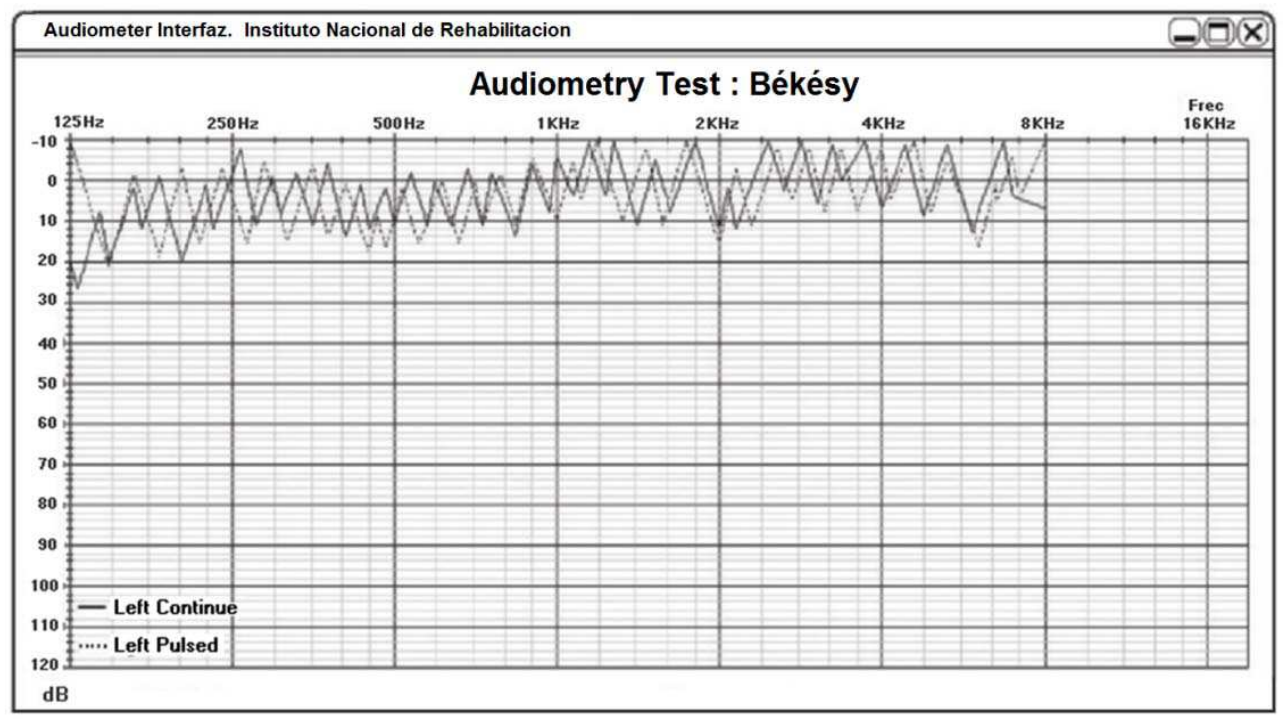

Fig. 5. A patient's Békésy test (Gutierrez et al., 2009)

Generally, an audiometric system controlled by a microprocessor (Penhaker \& Kijonka, 2011) is composed of two channels: one for test ear stimulus, and other as a non-test ear masker, as shown in the block diagram of Figure 6.

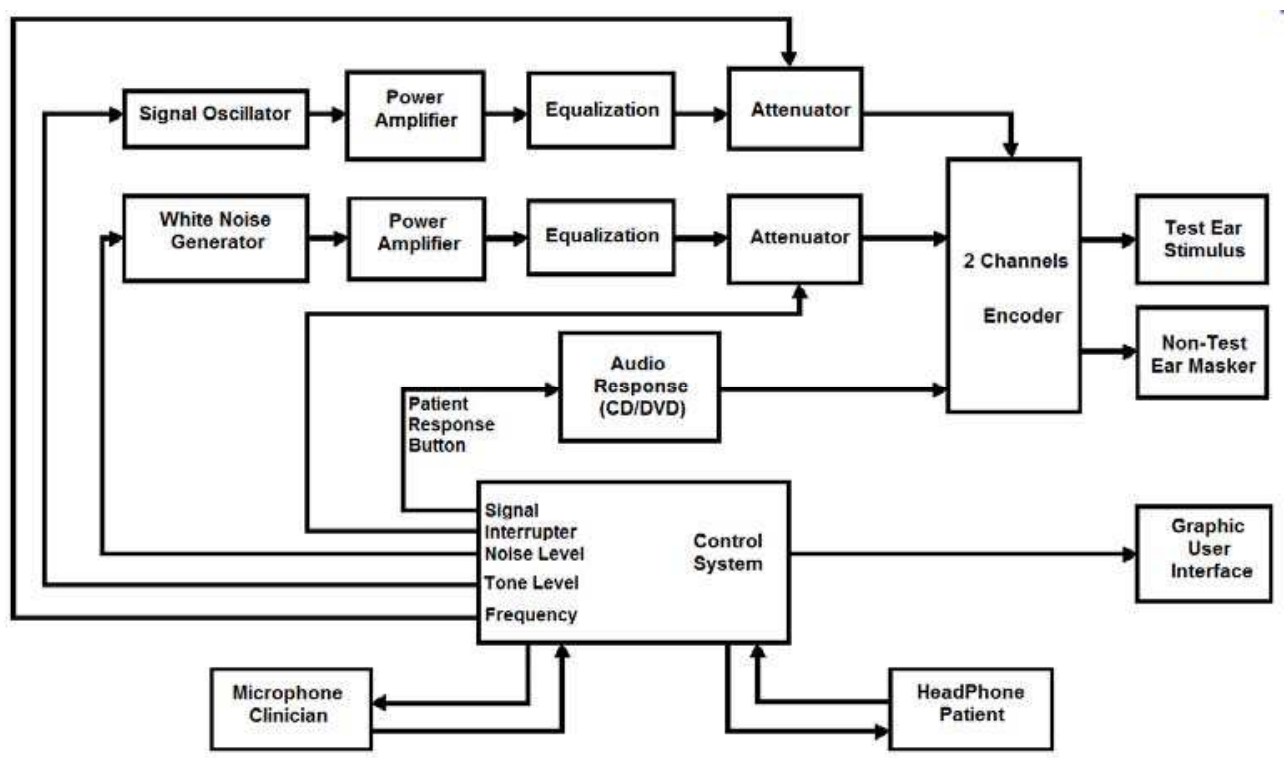

Fig. 6. General block diagram of an audiometer 
An audiogram is a chart that depicts the results of the audiometric study; on the x-axis, frequencies are represented in $\mathrm{Hz}$, and on the y-axis, the patient's hearing ability is expressed in $\mathrm{dB}$. Two charts are usually employed: one for the right ear, and one for the left. The right ear is graphed with a circle in red color, the blue color plot the left ear with an X. Symbols and notes should correspond to the recommendations and standards of the American Speech Language Hearing Association (ASHA).

ASHA guidelines for manual pure-tone threshold audiometry (Campbell et al., 2010); these guidelines contain procedures for performing a hearing diagnosis and for monitoring standard pure-tone threshold and include manual air-conduction and bone-conduction, masking. From the inception of modern audiometric technology, staff at the Department of Audiology at the Massachusetts Eye and Ear Infirmary began using an extension of the standard symbols for designating "response at limit" and responses found using speakers (Halpin, 2007). These symbols represent new exploratory developments and are not part of the ASHA standard symbol.

The NOAH-3 ${ }^{\mathrm{TM}}$ System (Hearing Instrument Manufacturers' Software Association, 2000) is a database that integrates software applications from the several manufacturers of audiologic devices, including Madsen ${ }^{\mathrm{TM}}$ (Madsen Electronics, 2004), Amplaid ${ }^{\mathrm{TM}}$, Interacustic ${ }^{\mathrm{TM}}$, Benson Medical $^{\mathrm{TM}}$. The main purpose of NOAH is to control data exchange from an audiometer to a personal computer, among other applications. The transmitted information is introduced into a database that is manipulated and processed to obtain audiograms, tables, measurements, and statistics, as well as to save and print the patient's study.

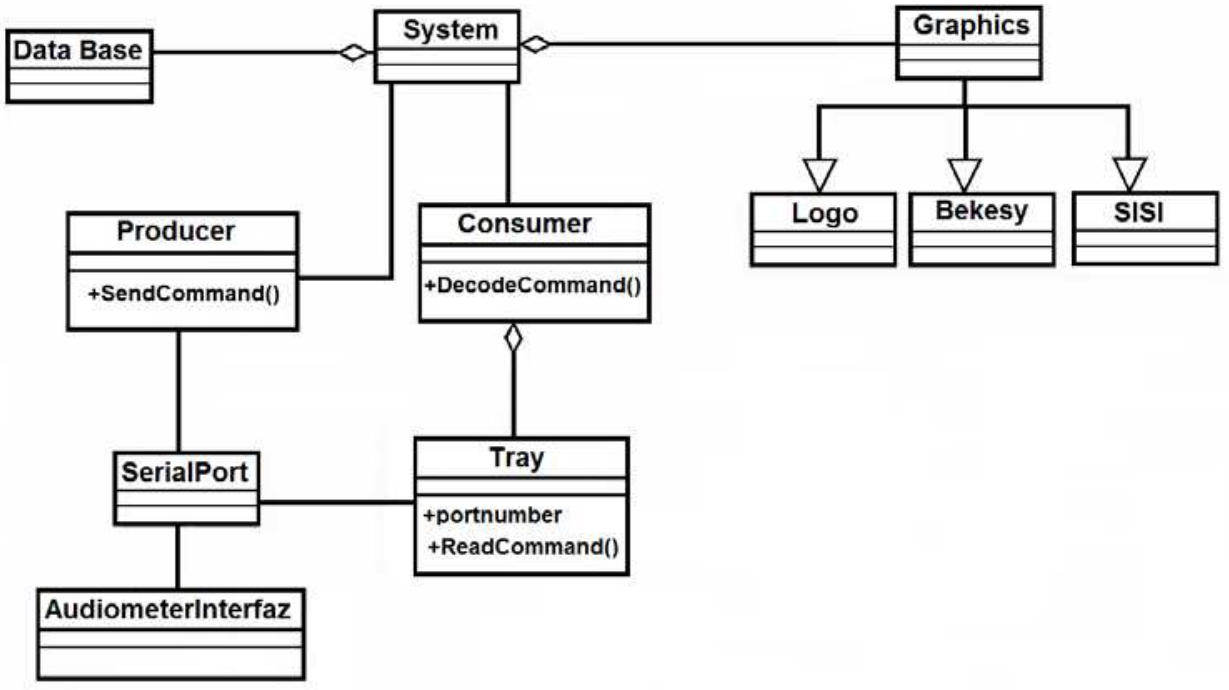

Fig. 7. Overview Producer-Consumer Architecture for the Audiometer Interface.

The NOAH-3 ${ }^{\mathrm{TM}}$ System does not work with certain special tests (SISI, Békésy) and some audiometers, for example, Madsen ${ }^{\mathrm{TM}}$ (Gutiérrez et al., 2009), and it is not possible to transfer data for processing or printing these special tests. When the audiometer is turned off, or 
when new patient data is introduced, the information of the previous test is lost. There is no database and the hardcopy audiograms are not designed for long term storage because the audiometer has a thermal printer.

This limitation is a problem for the specialist, because he/she needs to store the patient's test data so that this information can be used in clinical and research audiometric protocols. Some authors (Gutiérrez et al., 2009) have described the design and implementation of a communication and graphical module for transmitting, processing, printing, and storing the patient's special audiometric studies as a substitute for the NOAH-3 ${ }^{\mathrm{TM}}$ System (see Figure 7).

\subsubsection{Tympanometry}

The Impedance Audiometry or most commonly used Tympanometry, is a magnitude that examines the condition of the middle ear, the status and mobility of the eardrum (tympanic membrane). The equipment produces variations of air pressure in the ear canal by means of a probe measuring the middle ear's acoustic resistance. The secondary purpose of this examination is to evaluate the acoustic reflex pathway which includes the 7th and 8th cranial nerves and the brain stem. Furthermore, tympanometry permits a distinction between sensorineural and conductive hearing loss when results are not apparent via Weber and Rinne testing. It is also helpful in the diagnosis of otitis media by demonstrating the presence of middle-ear effusion. When sound impacts on the eardrum, part of the sound is absorbed and sent via the middle to the inner ear, while the remaining part of the sound is reflected. When the eardrum is inflamed over a long period of time, it can become stiff and heavy and the majority of the sound is reflected; therefore less sound reach the inner ear. Among other things, tympanometery assesses cochlear integrity and evaluates acoustic impedance, i.e., the degree of difficulty that the middle ear and ossicles encounter for the passage of sounds, as a result of the mass, stiffness and ossicular disruption of the auditory system. If there is fluid behind the ear-drum, it will not move back and forth from its resting position when pressure is applied. Tympanometry is thus affected by the mass, mobility, and resistance systems of the external and middle-ear cavities.

The instrument, or tympanometer, applies air pressure to the eardrum and measures the reflected sound. Inside the instrument's probe, a small loudspeaker is installed that emits a tone, typically at $226 \mathrm{~Hz}$, through a tube into the auditory canal in front of the eardrum. The canal's air pressure is altered between +200 and -400 decapascals (dapa), at which the sound strikes the tympanic membrane, causing middle-ear vibration, which in turn results in the perception of hearing. Some of this sound is reflected back and picked up by another tube, which is connected to the microphone inside the probe that receives the sound. Together with a third tube, all three are inserted nearly into the eardrum and are made airtight against outside pressure by the ear tip. A manometer and a pump, which can produce both positive and negative pressure, are connected to tube C. Less sound is reflected into the microphone when the eardrum is stiff and the eardrum transmits the majority of the sound via the middle to the inner ear. Highest compliance is normally reached with air pressure that corresponds to the outside pressure. During tympanometric measurement, a continuous change in positive and negative pressure is produced by the instrument's pump in the outer middle auditory canal. This test should not be performed in infants below 7 months of age because the suppleness of the external canal's cartilage may produce misleading results. 
Normally, air pressure in the ear canal is the same as ambient pressure. Also, under normal conditions, air pressure in the middle ear is approximately the same as ambient pressure because the Eustachian tube opens periodically to ventilate the middle ear and to equalize pressure. In a healthy individual, maximum sound is transmitted through the middle ear when ambient-air pressure in the ear canal is equal to the pressure in the middle ear.

The general term employed to describe how energy is transmitted through the middle ear is admittance. The impedanciometer measures reflected sound and expresses it in $\mathrm{ml}$ as admittance to or compliance with the pressure in $\mathrm{daPa}$, plotting the results on a chart known as a tympanogram, which is illustrated in Figure 8. The maximum compliance occurs when the pressure of the external auditory canal and the middle ear becomes equal. It is only at this pressure that maximal acoustic transmission takes place through the middle ear. Thus, the compliance peak indicates the pressure of the middle ear, implying the efficacy of the Eustachian tube function. The height of the compliance peak indicates the mobility/ stiffness of the tympanic membrane or of the middle-ear cavity.

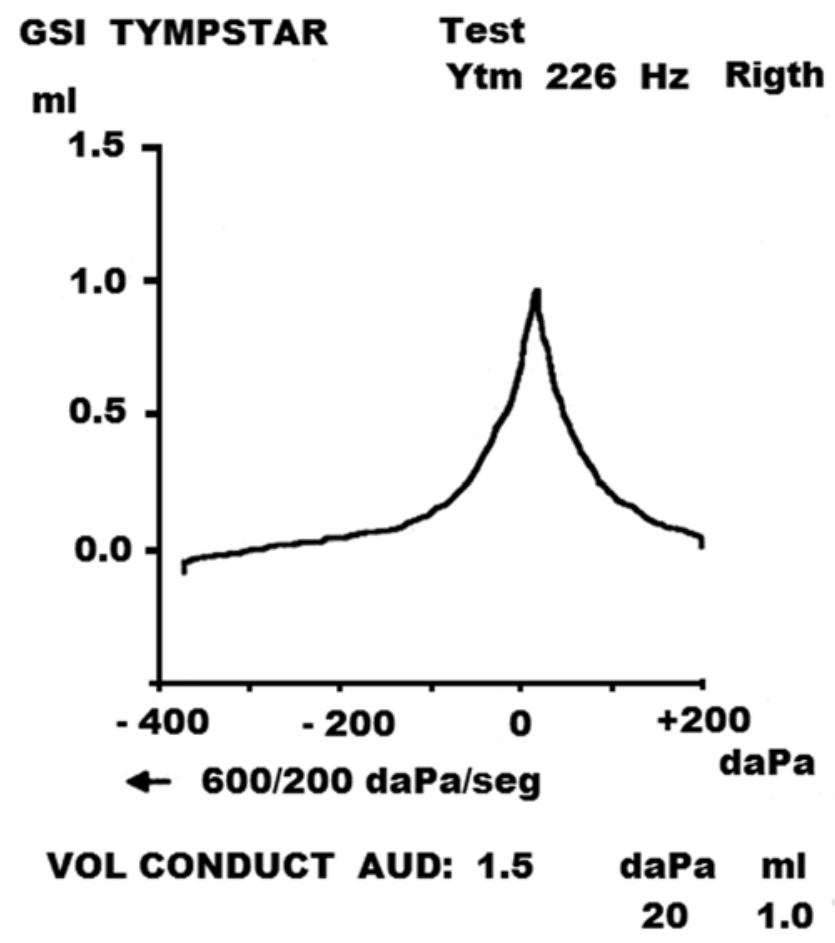

Fig. 8. Tympanogram of a normal subject, their canal's air pressure is altered between +200 and -400 dapa at $226 \mathrm{~Hz}$.

This test is not a hearing evaluation, but is rather a measure of energy transmission through the middle ear. It should not be used to assess hearing sensitivity and the results of this test should always be viewed in conjunction with pure-tone audiometry. Figure 9 presents the block diagram of a portable, hand-held tympanometer. Manufacturers, such as Welch Allyn, 
have marketed the invention registered by Heller et al, (Heller et al., 1987). This instrument has the capacity has the capacity of performing the test and of displaying and storing data.

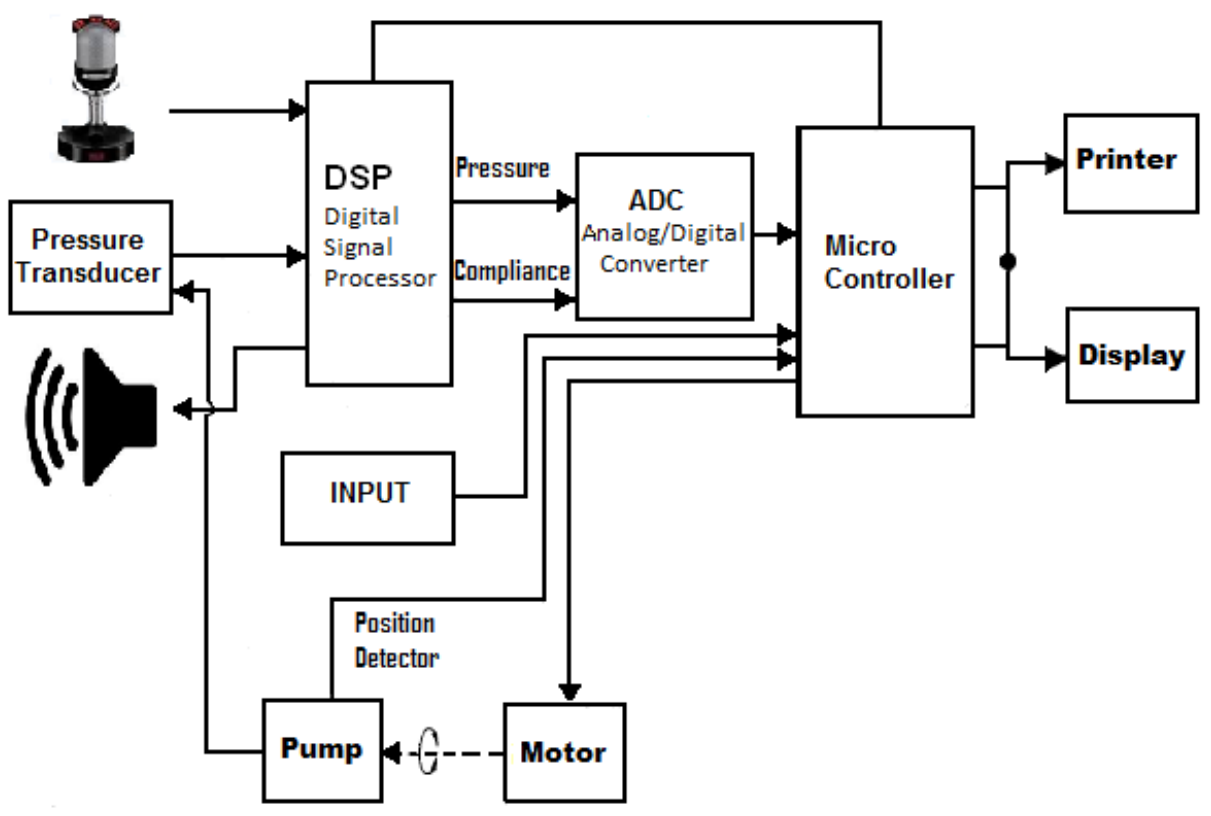

Fig. 9. General block diagram of a hand-held tympanometer.

\subsubsection{Otoacoustic emissions}

Otoacoustic Emissions (OAE) may occur spontaneously or may be evoked by acoustic stimulation, appearing to originate from within the cochlea and propagating through middle ear structures to the external auditory meatus. OAE are acoustic energy leakages from the biochemical reactions (echoes) of a healthy cochlea that possess a latency of 2-20 msec. If an emission by the cochlea is present, it is likely that hearing is normal at that frequency; those with a hearing loss greater than 25-30 dB usually do not produce these soft sounds. Auditory neuropathy may have OAE even though the hearing loss may be profound.

To measure OAE, the equipment produces a quiet, clicking sound that is emitted by the loudspeaker and OEA is measured with a small probe inserted into the ear canal; recording of the response signal is captured with the aid of a sensitive microphone (Choi, 2011). A number of response epochs must be averaged to improve the signal-to noise ratio (SNR) and produce a clear waveform. Mathematical methods are used for evaluation of the signal, such as Fast Fourier (FF) and Wigner-Ville transforms (WVT), Digital filtering, and Correlation analysis (CA) (Buller, 1997), or Hilbert-Huang transform (HT) for detection of OAE and Time-Frequency Mapping (Janušauskas et al., 2006). The measuring system employed to detect otoacoustic emissions consists of the following several parts, as illustrated in Figure 10: a measuring probe that includes a microphone and loudspeaker; a low-noise 
preamplifier and amplifier signal; an Analog-to-digital converter (ADC), and Digital Signal Processing (DSP) based on a central processing unit that provides ultra-fast calculation, such as filtering, averaging, FF, WVT, CA or HT in order to obtain otoacoustic emissions response. Additionally, the equipment must be accompanied by the printing and displaying module.

Because the subject being tested is not required to respond, this is an ideal test method for neonates and infants or for those who cannot be evaluated using conventional techniques (Buz \& Bower, 2009). OAE are valuable in testing for ototoxicity, detecting blockage in the outer ear canal, as well as the presence of middle-ear fluid and damage to the cochlea outer hair cells.

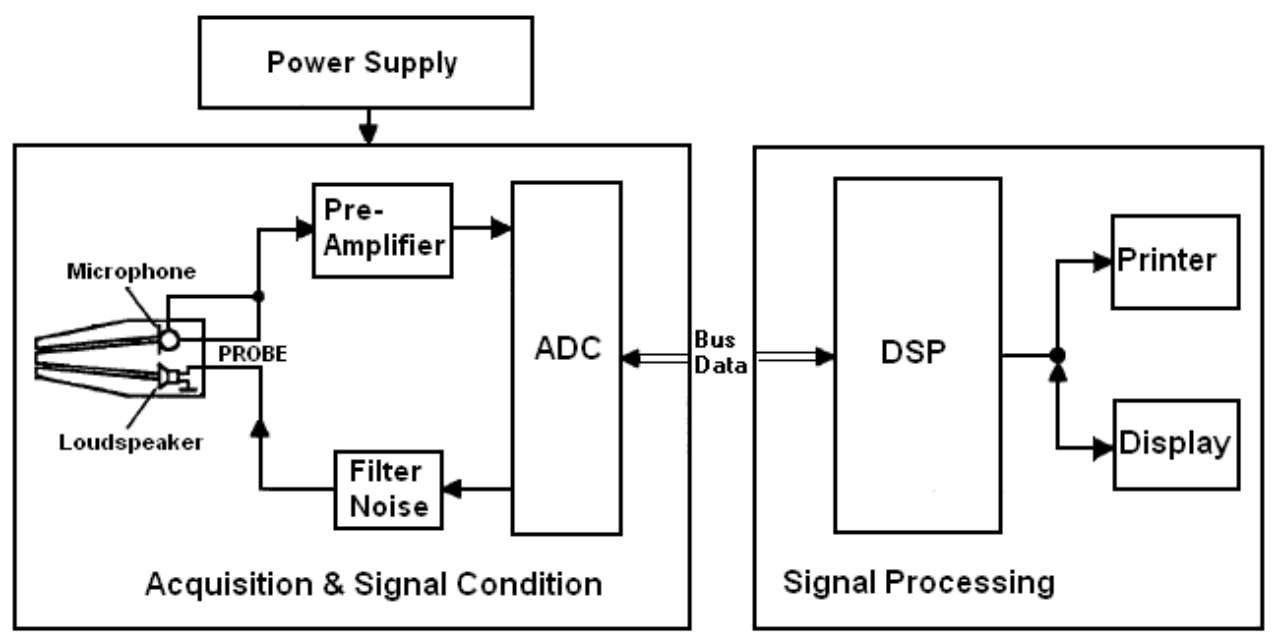

Fig. 10. Block Diagram of the measuring system used to detect OAE

\subsubsection{Stem cell evoked potentials}

The Vestibular Evoked Myogenic Potential is a test that is frequently performed on patients experiencing dizziness or balance problems. It evaluates additional portions of the inner ear providing a more complete evaluation of the vestibular system which controls balance. Electrodes are placed on the patients head and neck and a loud sound is delivered through inserted earphones. This test is very useful to screen infants and children under 5 years of age for hearing loss.

Auditory Brainstem Response is an electrical potentials activity in the brain that occurs in response to a sound. The test provides information on the cochlea and brain pathways for hearing. Three small disk electrodes are pasted onto the head and neck, and brain wave activity is recorded while the patient listens to a clicking sound. Soft headphones are placed into the patient's ears and quiet clicking sounds are played through the earphones.

Depending on the amount of time elapsing between the "click" stimulus and the auditory evoked response, potentials are classified as early $(0-10 \mathrm{msec})$, middle $(11-50 \mathrm{msec})$, or late 
(51-500 msec). Early potentials reflect electrical activity at the cochlea, eighth cranial nerve, and brain-stem levels, while later potentials reflect cortical activity. In order to separate evoked potentials from background noise, a system computer, as shown in Figure 11 (Nicolet ${ }^{\mathrm{TM}} \mathrm{EMG} / \mathrm{PE}$ ), analyzes how well the ears respond to the sound by averaging auditory evoked responses at 1,000 to 2,000 clicks at least. Early evoked responses may be analyzed to estimate the magnitude of hearing loss and to differentiate among cochlear, eighth nerve, and brainstem lesions.

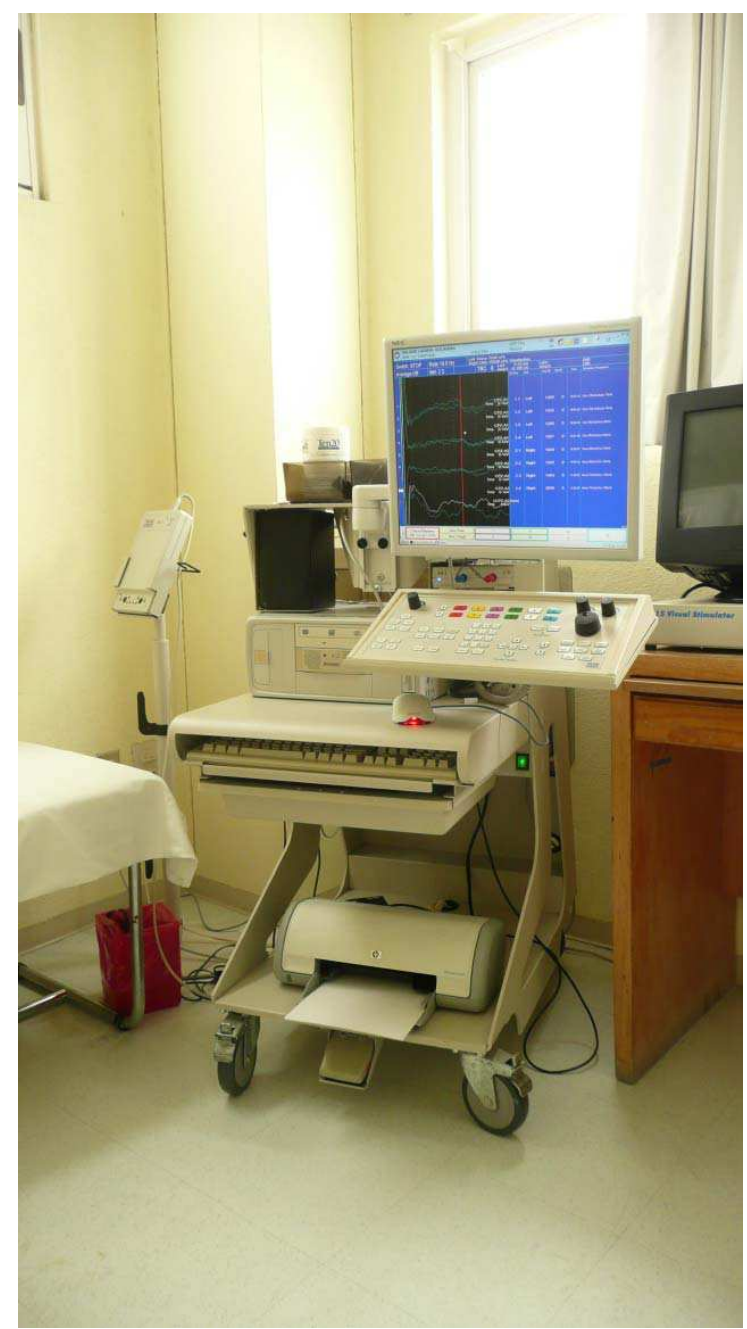

Fig. 11. Evoked Potential/EMG measuring system

For purposes of neonatal screening, only limited auditory evoked potentials or limited evoked otoacoustic emissions are considered medically necessary. Neonates who fail this screening test are then referred for comprehensive auditory evoked response testing or 
comprehensive otoacoustic emissions. Comprehensive auditory evoked response testing and comprehensive otoacoustic emissions are considered experimental and investigational for neonatal screening because there is a lack of evidence of the value of comprehensive testing in limited auditory evoked potentials or limited otoacoustic emissions for this indication.

\subsubsection{Videonystagmography}

This technique is used to evaluate the function of the vestibular system; the inner-ear portion may be the cause of any balance or dizziness problems. The instrument records eye movements, most notably involuntary eye movements called nystagmus. Eye movements are recorded by using infrared goggles. There are three evaluations, including: 1) following a light as it moves in different ways; 2) lying flat on the examination table and the subject's moving his/her head left or right, and 3) stimulating the vestibular system with warm and cool air or water.

\subsection{Hearing assistance technology}

Hearing loss can be categorized according to which part of the auditory system is damaged, the degree or severity of impairment and the configuration or pattern of injury across tones. There are three basic types of hearing loss: conductive hearing loss, sensorineural loss, and mixed hearing loss. Each of these should be approach with assistive devices, such as hearing aids and cochlear implants, so that individual best adapt to managing conversations and take charge of their communication.

\subsubsection{Hearing aids}

From; tremendous advances in technology of amplification have occurred from the days that ear trumpets and animal horns were used to help to transmit sounds into the ear. A hearing aid is an electroacoustic device that typically fits in or behind the wearer's ear. It is designed to amplify and modulate sound in order to direct the flow of sound into the ear canal, thus enhancing sound quality (Killion, 1997). Hearing aids differ in design, size, ease of handling, volume control, amount of amplification, and the availability of special features such as digitized processing. Their basic functional parts include a microphone to pick up sound and an associated preamplifier, an automatic gain control circuit, a set of active filters, a mixer and power amplifier to make the sound louder, and an output transducer or receiver (a miniature loudspeaker that can be made in integrated form with a field-effect transistor preamplifier) to deliver the amplified sound into the ear. All electronic circuitry is packaged in housing works on a battery. The use of multiple channels in this design provides different compression characteristics for different frequency ranges. Typically, crossover frequencies of the channels and compression characteristics can be adjusted with potentiometers or digital control.

Conventional analog hearing aids are designed for a particular frequency and utilize a fixed or dedicated directional microphone. Although some adjustments are necessary, the aid essentially amplifies all sounds (speech and noise) in the same manner. The directional microphone mode, amplifies sounds from in front more than sounds from other directions. (Berger, 1984). 
Analog programmable hearing aids have a microchip that is programed for different listening environments. Program settings depend on the individual's hearing-loss profile, understanding of speech, and range of tolerance for louder sounds (Walden \& Walden, 2004). Even with the improvement that analog programmable offer, $25.3 \%$ of analog hearing aid users reported that they have a hard time listening in presence of high background noise. Approximately 1\% of the users reported difficulty in using the telephone. Examples of environments include quiet conversation in the home, noisy situations such as at a restaurant, or in large areas such as a theater.

In 1996, the Digital signal processing (DSP) chip was introduced into digital programmable hearing aids (Phillips et al., 2007). These hearing aids use digitized sound-processing algorithms to convert sound waves into digital signals. Key benefits of these include improvement in programmability, greater precision in fitting, management of loudness discomfort, control of acoustic feedback, and noise reduction. A processor chip in the aid analyzes the signals to determine whether the sound is noise or speech. It then makes modifications to provide a clear, amplified, distortion-free signal (Clopton \& Spelman, 2000).

Digital hearing aids are usually self-adjusting. The digital processing allows for more flexibility in programming the aid. Thus, the sound transmitted matches the patient's specific hearing-loss pattern. This digital technology is more expensive than that of the conventional analog, but it offers many advantages: these generally have a longer life span and may provide better hearing in different listening situations. Some aids can store several programs, i.e., when the listening environment changes, it is possible to change the hearing aid settings. This is usually done by pushing a button on the hearing aid or by using a remote control to switch channels. The aid can be reprogrammed by the Audiologist if the user's hearing or hearing needs change.

Of all of the advances in hearing aid technology in the last several years, perhaps the greatest has been the performance of directional microphones. The use of DSP in hearing aids has opened the door to the many different types of algorithms used in directional microphones. Digital technology offers many options, including automatic, automatic adaptive, multiband automatic adaptive, and, most recently, asymmetric directionality (Kerckhoff, 2008). Each of these options possesses benefits, but some also have limitations and may not prove to be as beneficial to the patient as advertised by hearing aid manufacturers.

Directional microphones were developed in an attempt to improve SNR performance. These microphones can employ different types of polar patterns, some of which have multiple nulls. The fixed directional microphone contains two sound ports and operates by acoustically delaying the signal entering the back microphone port and subtracting this from the signal entering the front port. This creates a null at an azimuth, corresponding to the location where the microphone is least sensitive, and which can be plotted graphically on a polar pattern (Chung, 2004). These patterns are predetermined; thus, the location of sound attenuation always remains the same. Therefore, if the interfering sound is located directly behind the patient, this design acts to attenuate the input level to the hearing aid at the $180^{\circ}$ null. If, however, the offending sound arrives from behind but not directly at, $180^{\circ}$, the microphone will be less effective in improving SNR. 
Several studies have reported the effectiveness of fixed directional microphones in improving SNR for the hearing aid user by at least $5 \mathrm{~dB}$, (Bilsen et al., 1993). Gravel, Fausel, and Liskow (Gravel et al., 1999) found that children listening with dual microphones achieved a mean improvement of $4.7 \mathrm{~dB}$ in SNR when compared with the omnidirectional condition.

Automatic directional microphones were subsequently developed so that patients would not have to bother with manually changing the hearing aid program or setting to the directional microphone mode. Automatic directional microphones utilize an algorithm in which the microphones switch automatically between omnidirectional and directional. Input level, signal location, and SNR are factors that contribute to determining when the microphones switch (Preves \& Banerjee, 2008).

The automatic microphone feature works well for patients who do not want to be concerned with manual switching between omnidirectional and directional modes. However, automatic switching can be problematic for patients when the microphone switches but the patient does not prefer switching, or if the switching takes place too rapidly and amplifies unwanted sounds such as a cough or a dog barking (Preves \& Banerjee, 2008). The other limitation with automatic directional microphones is that the null is fixed when in the hearing aid is in directional mode. Depending on the location of the noise source and the azimuth of the null in the microphone, there is the possibility that the noise source may not be maximally attenuated.

Although directional microphones have been shown to be successful in the laboratory, there is no guarantee that this success will be achieved in real-life situations for all hearing aid users, due to the difficulty that some persons have in manipulating the hearing aid's controls.

There are four hearing aids styles or configurations. These include the following: the In-thecanal (ITC) style; the In-the-ear (ITE) hearing instruments, which are very easy to operate even if the user has poor dexterity; the behind-the-ear (BTE) style, which is extremely flexible for all hearing loss types, and the Completely-in-the-canal (CIC) style, as depicted in Table 1 (Miller,2006).

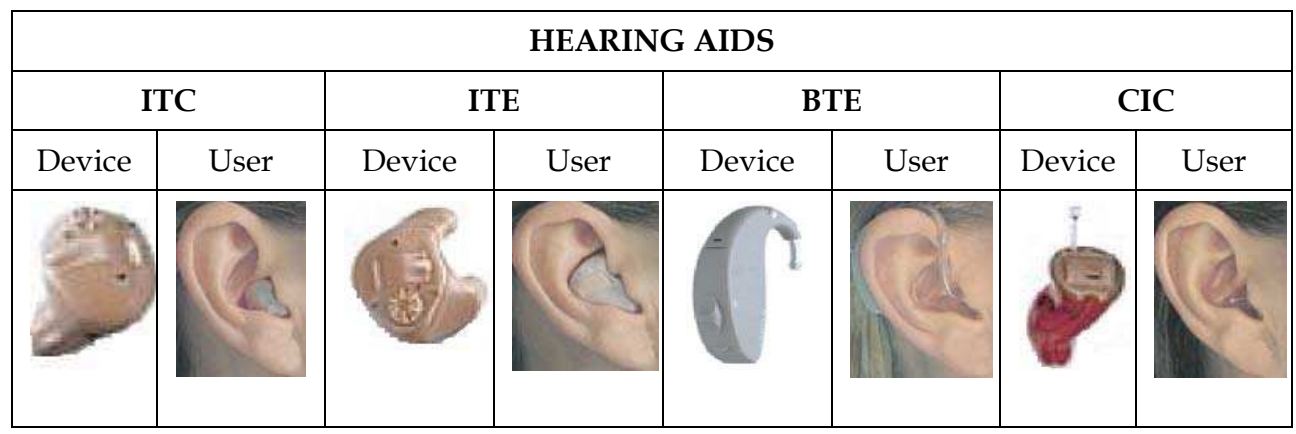

Table 1. Styles of Hearing Aids

There are many manufactures of hearing aids such as Viennatone ${ }^{\mathrm{TM}}$, Hansaton ${ }^{\mathrm{TM}}$, Bernafon $^{\mathrm{TM}}$, Oticon ${ }^{\mathrm{TM}}$, Siemens ${ }^{\mathrm{TM}}$, Sonic ${ }^{\mathrm{TM}}$, Unitron ${ }^{\mathrm{TM}}$, and Phonak $^{\mathrm{TM}}$. According to the Food 
and Drug Administration (FDA), the manufacture and sale of hearing aids must meet the following requirements:

1. Dispensers must obtain a written statement from the patient, signed by a licensed physician;

2. A patient aged 18 years or older can sign a waiver for a medical examination, but dispensers must avoid encouraging the patient to waive the medical evaluation requirement;

3. Dispensers must advise patients who appear to have a hearing problem to consult a physician promptly, and

4. FDA regulations also require that an instruction brochure be provided with the hearing aid that illustrates and describes its operation, use, and care.

The FDA Web site that provides standards for hearing aids is at http://www.accessdata.fda.gov/scripts/cdrh/cfdocs/cfStandards/Detail.CFM?STANDAR D_IDENTIFICATION_NO=14730

Recent developments in the access to newer forms of wireless transmission and improvements in coupling this technology with hearing aids not only enhance patients' abilities to use telephones or other external devices, but also allow improvement in SNR performance for better speech recognition through noise reduction algorithms.

\subsubsection{Cochlear implants}

A cochlear implant is a prosthetic inner-ear replacement that provides direct electrical stimulation to the inner ear's auditory nerve, allowing for perception of the sensation of sound. These devices are used for patients with severe-to-profound hearing sensorineural loss who cannot be helped with hearing aids. These implants can benefit patients with boneconduction thresholds as poor as $65 \mathrm{~dB}$ HL. Because of this damage, sound cannot reach the auditory nerve. With a cochlear implant, the damaged hair cells are bypassed and the auditory nerve is electronically stimulated directly (Spitzer, 2010).

Part of the cochlear implant is surgically implanted into the mastoid bone behind the target ear with a titanium screw (osseointegrated material), and a tiny electrode array is inserted into the cochlea at set intervals depending on the number of channels or number of frequency bands to excite (Medical Advisory Secretariat, 2002). The other part of the device is external and includes a microphone, a speech processor, and a transmitter coil.

The signal from the microphone is sent to the speech processor, which comes in two designs. It may be either a BTE model Nucleus Freedom ${ }^{\mathrm{TM}}$, which looks like a hearing aid, or a Body-worn device (BWD) that it attached to the belt, for example, the Cordelle II (European Assistive Technology Information Network, 2010), manufactured by Cochlear Deutschland GmbH \& Co. KG, as shown in Table 2.

The microphone looks like a BTE hearing aid. It picks up sounds-just as a hearing aid microphone does-and sends these to the speech processor. The speech processor is a computer that analyzes and digitizes the sound signals and sends them to a transmitter worn on the head just behind the ear. The transmitter sends the coded signals to a receiver implanted immediately under the skin. The internal or implanted parts include a receiver and electrodes. The receiver is just under the skin behind the ear. The receiver takes the 
coded electrical signals from the transmitter and delivers them to the array of electrodes that have been surgically inserted into the cochlea. The electrodes stimulate the fibers of the auditory nerve and sound sensations are perceived. Figure 12 depicts a series of stages of the speech processor of a typical cochlear implant and the associated processing waveforms at each stage (Miller, 2006, as cited in Loizou, 1998).

\begin{tabular}{|c|c|c|c|}
\hline \multicolumn{4}{|c|}{ COCHLEAR IMPLANTS } \\
\hline Device & User & Device & BMD \\
\hline 3 & &
\end{tabular}

Table 2. Styles of Cochlear Implants.

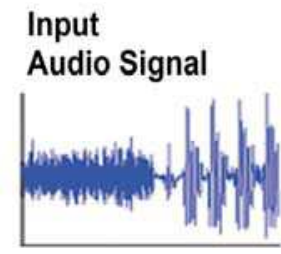

Microphone

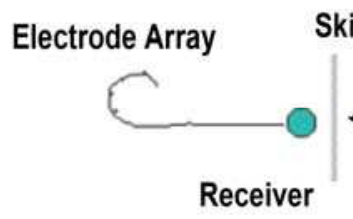

Skin
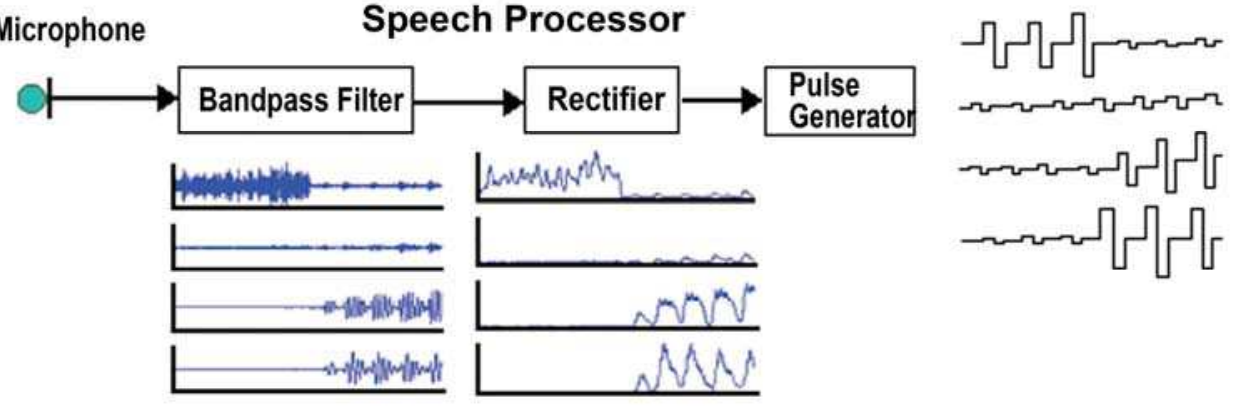

Fig. 12. Block Diagram of a typical cochlear implant and processing waveforms

\subsection{Hearing Assistive Technology Systems}

Other devices are employed to assist individuals with hearing impairment who have not previously experienced benefit with hearing aids or cochlear implants alone. Hearing assistive technology systems (HATS) are devices that can help patients function better in their day-to-day listening and communication situations. HATS can be used with or without 
hearing aids or cochlear implants to make hearing easier - and thereby reduce stress and fatigue. HATS must be directed toward resolving any one of the following situations: distance; noise, or reverberation that can create listening problems (Medical Services Advisory Committee, 2010).

\subsubsection{FM systems}

FM systems operate on special frequencies. A receiver worn around the neck transmits sound to the hearing aid. The sound comes from a transmitter microphone used by a speaker, although in many public places, the transmitter is built into the general sound system.

Because of their flexibility, mobility, and sturdiness, these systems are among the most commonly used HATS. Studies have shown that FM systems have the best results when implementation is carried out early in the amplification-fitting or cochlear-implant process. Also, infrared wireless headset are available for television listening and interface. However, there are other systems, denominated sound-field systems, which assist listening for all of the children in the classroom. The teacher speaks into a microphone transmitter and his/her voice is projected through speakers mounted around the classroom.

\subsubsection{High-frequency hearing loss}

Newer devices, such as the BAHA ${ }^{\mathrm{TM}}$ system manufactured by Entific Medical (Medical Advisory Secretariat, 2002) have been developed for patients diagnosed with unilateral profound sensorineural hearing loss, also referred to as single-sided deafness. Other devices have been designed for patients exhibiting severe high-frequency transposition hearing loss and comprise self-learning features on hearing aids and cochlear implants that allow integrate of actual measurements. Finally, an infrared wireless headset is used with television for listening at a higher volume than others sitting in the same room. Bluetooth interface allows persons to hear telephone conversations more easily, amplifying any devices that employ this technology.

\section{Conclusion}

The present section provided a brief guide on equipment for diagnosis of deafness and hearing assistive technology.

Although, audiology equipment for evoked potentials and otoacoustic emissions provides highly relevant information deriving from hearing damage, in future, new technological developments should be directed toward improving the hearing test. The research will continue to study algorithms for more accurate, physically realistic modeling of the cochlea, which should assist in the process of diagnosing local inner-ear problems.

Audiometers, Tympanometers and other electronic equipment for hearing diagnosis must be designed taking into account specific data formats, communication protocols and interoperability standards, as such HL7 (Health Level Seven) to send data from audiology equipment to electronic medical record, then it is possible to share and use data for research and clinical propose. 
Potential areas for improving hearing aids and cochlear implants include frequency response by analyzing sound across several bands, enhancing the signal-to-noise ratio with adaptive filtering, installing additional detectors for monitoring the environment. Subsequently applying average algorithms to turn the acoustic signal into a frequency map and for the application of noise reduction while maintaining high gain in bands in which speech is detected., will improve speech understanding in noise.

For patient with nerve deafness, one goal is to restore hearing with cochlear electrode implants in order to stimulate the nerve endings directly. However, despite electrode stimulation of nerves at the correct place along the cochlea, the perception of high frequency has not been achieved to date.

Finally, the research on FM and infrared systems, Bluetooth adaptors, and other novel communication techniques and devices continues for helping patient to achieve greater comfort, higher satisfaction-of-fit and less fatigue, when he/she is exposed to a noisy environment

\section{Acknowledgment}

We thank the staff of the Department of Biomedical Engineering as well as that of the Audiology and Electrodiagnosis Services for the support received in the collection of information.

\section{References}

Acoustic Systems MD. (2000). International. Audiometric Testing Suites Field Performance Verification, Instruction Manual, pp.(2)

Aguilera, S.; Pescador, F.; Godino, JI. \& Novillo R. (1997). Improvement of a Spanish Speech Processing System. In: Advancement of Assistive Technology, Anogianahis G., Bühler CH. \& Soede M., pp.(115-119), IOS Press Ohmsha, ISBN:9051993617

Aitkin, L. (1990). The Auditory Cortex: Structural and Functional Bases of Auditory Perception, Chapman and Hall, ISBN:04123249039780412324901, London; New York

ASTM E336 - 10. (2011). Standard Test Method for Measurement of Airborne Sound Attenuation between Rooms in Buildings, available from: http://www.astm.org/Standards/E336.htm

Australian Hearing Group. (2001). Manual of Speech Perception. National Acoustic Laboratories, pp. (10-32), available from: http://www.nal.gov.au/dvd-cdreport_tab_manual-of-speech-perception.shtml

Berger, KW. (1984). The hearing aid, its operation and development, In: The Hearing Aid. $3^{\text {rd }}$ ed. Thieme Medical Publishers, ISBN:0387955836

Bilsen, F.; Soede, W. \& Berkhout, A. (1993). Development and assessment of two fixed-array microphones for use with hearing aids. Journal of Rehabilitative Research Dev, Vol. 3, No.1, pp.(73-81), ISSN:0748-711

Buller, G. \& Sa $\beta$, T. (1997). Implementing a Signal Processing Subsystem to Detect Stimulated Otoacoustic Emissions Using the TMS320C31 DSP. Texas Instrument., pp.(9-15), USA 
Buz, A. \& Bower, Ch. (2009). Hearing Assessment in Infants and Children: Recommendations Beyond Neonatal Screening. Pediatrics Vol. 12, No.1, (September 2009), pp.(40-52), ISSN: 0031-4005

Campbell, J.; Graley, J.; Meinke, D.; Vaughan, L.; Aungst, R. \& Madison, T. (2010). Guidelines for Manual Pure-Tone Threshold Audiometry, In: ASHA Main Page, 2011, Available from: http://www.asha.org/docs/html/GL2005-00014.html

Choi, Y. (2011). Method and Apparatus for Measuring Otoacoustic Emission. Patent Application Publication, No. US2011/0166806A1, (Jul 7, 2011), pp.(1-12), available from: patents.com/us-20110166806.html

Chung, K. (2004). Challenges and recent developments in hearing aids: Part I. Speech understanding in noise, microphone technologies and noise reduction algorithms. Trends in Amplification, Vol. 1 No. 1, pp.(83-124), ISSN:1084-7138

Clopton, B. \& Spelman F. (2000). Auditory System, In: The Biomedical Engineering Handbook, Bronzino, J., pp. (83-95), CRC IEEE PRESS, ISBN: 0-8493-0461-X, Boca Raton Florida USA

European Assistive Technology Information Network. (2010). Assistive Technology Products. EASTIN Group. Available from: http://www.eastin.eu/enGB/searches/products/detail/database-rehadat/product-897460

Ghani, J.; Ellermeier, W. \& Karin Zimmer K. (2005). A test battery measuring auditory capabilities of listening panels, Proceedings of Forum Acusticum, ISSNs: 1610-1928, Budapest, Hungary, (August 29 - September 2 2005)

Goldfain, E.; Slawson, S.; Andreassen, E.; Kuiper, C.; Staples, E. \& Lia R. (2008). Otoscope. United States Patent No. 7399275, pp.(1-13), available from: http://patents.justia.com/2008/index.html

Gravel, J., Fausel, N., \& Liskow, C. (1999). Children's speech recognition in noise using omnidirectional and dual microphone hearing aid technology. Ear and Hearing, Vol. 20, No. 1, pp.(1-11), ISSN:01960202

Gutiérrez, J.; Barraza, FE.; Guadarrama, A.; Núñez, MA.; Delgado, RE. \& Gutiérrez, I. (2009) Communication Interface and Graphic Module for Audiometry Equipment. Biomedical Instrumentation \& Technology. Vol. 43, No. 6, (December, 2009), pp.(484488), ISSN: 0899-8205-43.6.484

Halpin, C. (2007). Something new for the audiogram: Alternative symbol developed for response at limit. The ASHA Leader, (2007, Jan. 23), Vol. 12 No 1, pp.(5-19)

Heller, J.; Kugler, A.; Longacre, A. \& Williams, D. (August 25, 1987). Tympanometer Portatil. United States Patent No. 4688582, available from: es.patents.com/us-4688582.html

Hearing Instrument Manufacturers' Software Association. (2000). NOAH System Software In: User's NOAH Manual, HIMSA, pp.(6-25) Version 3. A/S

Janušauskas, A.; Maroza, V. \& Lukoševicius A. (2006). The Hilbert-Huang Transform for Detection of Otoacoustic Emissions and Time-Frequency Mapping, Informatica, Vol. 17, No. 1, (March 2006), pp.(25-38), ISSN:0868-4952

Kerckhoff, J.; Listenberger, J. \& Valente, M. (2008). Advances in Hearing Aid Technology. Communication Science and Disorders, Vol. 35, pp.(102-112), ISSN:1092-5171

Khandpur, R.S. (2005). Biomedical Instrumentation Technology and Applications, Ed. McGrawHill, ISSN: 0071447849 9780071447843, New York USA 
Killion, MC. (1997). Hearing aids: Past, present, future and moving toward normal conversation in noise. British Journal of Audiology, Vol. 31, No. 3, (October 1997), pp.(141-148), ISSN:0300-5364

Loizou, PC. (1998). Introduction to cochlear implants. IEEE Signal Processing Mag, ISSN:07395175, (September 1998), pp.(101-130)

Madsen Electronics. (2004). 922Orbiter In: Operation Manual of Clinical Audiometer. MADSEN, pp.(102-105), Version 2.X. Part No.7-26-110, Doc. No. 7-26-1100/0, Copenhagen, Denmark

MAICO. (2007). Operating Instructions Race Car Tympanometer. 1162-0703 Rev A, pp.4-15.

Marullo, T.; Mazza, G. \& Bianchi, F. (1967). Evaluation of vocal acumetry. PubMed: 5612940, Vol. 43 No. 4, (August 1967), pp.(217-243),ISSN:0899-8205

Medical Advisory Secretariat. (2002). Bone anchored hearing aid: an evidence based analysis. Ontario Health Technology Assessment Series Vol. 2, No.3

Medical Service Advisory Committe. (2010). Middle ear implant for sensorineural, conductie and mixed hearing losses, Cormmonwalth of Australia, (November, 2010), ISBN: 978-1-74241-348-8

Miller, G. (2006). Sensory Organ Replacement and Repair, (1 ${ }^{\text {st }}$ Edition), Ed Morgan \& Claypool Publishers' Series, ISBN:1598290630, San Rafael, CA USA

Montano, J. \& Spitzer, J. (2009). Adult Audiologic Rehabilitation, Ed Plural Publishing, ISBN: 9781597562508, San Diego, CA USA

National Health and Nutrition Examination Survey. (2003). Audiometry Procedures Manual, (January 2003), pp.(2.1-2.55)

Penhaker, M. \& Kijonka J. (2011). Audiometry for Teaching Experiment in PowerLabSystems, In: Electrical Power Systems and Computers, Xiaofeng W, pp.(831-838), Springer-Verlag, ISBN:978-3-642-21746-3, Berlín

Phillips, W.; Knight, L.; Caldwell, N. \& Warrington, J. (2007). Policy through procurementThe introduction of digital signal process (DSP) hearing aids into the English NHS. Health Policy, Vol. 4, No. 1, pp.(77-85), ISSN:0168-8510

Preves, D. \& Banerjee, S. (2008). Hearing aid instrumentation signal processing and electroacoustic testing. In: Audiology treatment, Valente, M.; Hosford-Dunn, H. \& Roeser, R., pp.(1-35), Thieme Medical, New York USA, ISBN:978-3-13

Salesa, E.; Bonavida, A. \& Perelló, J. (2005). Tratado de Audiología, (1a Edición), ElsevierMasson., ISBN: 844581554-7, Madrid España

Spitzer, JB. (2010) Implantable Devices for Rehabilitation of Persons with Hearing Loss. In : Implantable Technologies. Seminars in Hearing, Spitzer JB., pp.(3-6), Thieme-Stratton, New York USA, ISSN:0734-0451

Steele, CH.; Baker, G.; Tolomeo, J. \& Zetes-Tolomeo D. (2000). Cochlear Mechanics, In: The Biomedical Engineering Handbook, Bronzino, J., pp. (581-594), CRC IEEE PRESS, ISBN 0-8493-0461-X, Boca Raton Florida USA

Walden, T. \& Walden, B. (2004). Predicting success with hearing aids in everyday living. Journal of the American Academy of Audiology, Vo. 15, No. 5, pp. (342-352), ISSN:10500545 


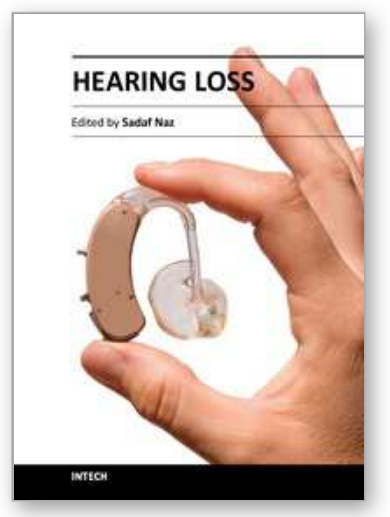

\author{
Hearing Loss \\ Edited by Dr. Sadaf Naz
}

ISBN 978-953-51-0366-0

Hard cover, 406 pages

Publisher InTech

Published online 28, March, 2012

Published in print edition March, 2012

Authored by 17 international researchers and research teams, the book provides up-to-date insights on topics in five different research areas related to normal hearing and deafness. Techniques for assessment of hearing and the appropriateness of the Mongolian gerbil as a model for age-dependent hearing loss in humans are presented. Parental attitudes to childhood deafness and role of early intervention for better treatment of hearing loss are also discussed. Comprehensive details are provided on the role of different environmental insults including injuries in causing deafness. Additionally, many genes involved in hearing loss are reviewed and the genetics of recessively inherited moderate to severe and progressive deafness is covered for the first time. The book also details established and evolving therapies for treatment of deafness.

\title{
How to reference
}

In order to correctly reference this scholarly work, feel free to copy and paste the following:

Josefina Gutierrez (2012). Technology for Hearing Evaluation, Hearing Loss, Dr. Sadaf Naz (Ed.), ISBN: $978-$ 953-51-0366-0, InTech, Available from: http://www.intechopen.com/books/hearing-loss/technology-forhearing-evaluation

\section{INTECH}

open science | open minds

\section{InTech Europe}

University Campus STeP Ri Slavka Krautzeka 83/A 51000 Rijeka, Croatia Phone: +385 (51) 770447

Fax: +385 (51) 686166 www.intechopen.com

\section{InTech China}

Unit 405, Office Block, Hotel Equatorial Shanghai No.65, Yan An Road (West), Shanghai, 200040, China 中国上海市延安西路65号上海国际贵都大饭店办公楼405单元 Phone: +86-21-62489820

Fax: +86-21-62489821 
(C) 2012 The Author(s). Licensee IntechOpen. This is an open access article distributed under the terms of the Creative Commons Attribution 3.0 License, which permits unrestricted use, distribution, and reproduction in any medium, provided the original work is properly cited. 